Www.jmscr.igmpublication.org

Impact Factor (SJIF): 6.379

Index Copernicus Value: 79.54

ISSN (e)-2347-176x ISSN (p) 2455-0450

crossrefDOI: https://dx.doi.org/10.18535/jmscr/v6i9.171

Journal Of Medical Science And Clinical Research

\title{
A Correlational Study of Serum Lipoprotein (A) Level and Diabetic Nephropathy in Type 2 Diabetes Mellitus Patients
}

\author{
Authors

\section{Dr Sriharsha Kulkarni ${ }^{1}$, Dr Vishwanath C Patil ${ }^{2}$, Dr Muralidhar H. $^{3}$} \\ ${ }^{1}$ Assistant Professor, Department of General Medicine, S.S. Institute of Medical Sciences \& Research \\ Centre, Davangere, Karnataka, India \\ ${ }^{2}$ Assistant Professor, Department of General Medicine, S.S. Institute of Medical Sciences \& Research \\ Centre, Davangere, Karnataka, India \\ ${ }^{3}$ Post Graduate, Department of General Medicine, S.S. Institute of Medical Sciences \& Research Centre, \\ Davangere, Karnataka, India \\ *Corresponding Author

\section{Dr Muralidhar H}

Post Graduate, Department of General Medicine, S.S. Institute of Medical Sciences \& Research Centre, Davangere, Karnataka, India

\begin{abstract}
Background and Objectives: Diabetes is the most common endocrine disorder and a burdensome chronic disease in the world today. The objective of the study is to assess the Microvascular complication-diabetic nephropathy in patients with type 2 DM with respect to their serum levels of Lp (a).

Methodology: The present one year correlation study was conducted in the Department of Medicine, Navodaya Medical College Hospital and Research Centre, Raichur on 100 patients diagnosed to have type 2 DM, proved by laboratory reports during the period of August 2013 to July 2014. A detailed history, physical examination and laboratory tests were done. Serum lipoprotein (a) levels were measured by randox immunoturbido-metric immunoassay. Fasting blood sugar levels along with other relevant investigations were also done.

Results: The results of the study showed that, Lp (a) values progressively increased as age increased. Diabetic patients with nephropathy had increased levels of $L p(a)$. The present study indicated that better the glycemic control, lesser the mean Lp (a) levels. Lp (a) levels may be used as a screening or predictive tool for development of Microvascular complication like diabetic nephropathy in Diabetic patients.

Conclusion and Interpretation: $L p(a)$ may be an independent risk factor for the development of diabetic nephropathy in type 2 diabetes mellitus.

Keywords: Lipoprotein (a); Diabetes mellitus; Nephropathy.
\end{abstract}

\section{Introduction}

Diabetes is the most common endocrine disorder and a burdensome disease in the world. Lp (a) is a plasma complex composed of apolipoprotein (a) [Apo (a)] covalently linked to
Apo B-100 by disulfide bridges. Because of the structural similarity of Apo (a) to plasminogen, Lp (a) has been suggested to have antifibrinolytic properties. 
Dyslipidemias frequently associated with type 2 diabetes mellitus (DM) are hypertriglyceridemia, hypercholesterolemia, low high density lipoprotein (HDL), preponderance of small and dense low density lipoprotein (LDL), and elevated levels of Lipoprotein (a) [Lp (a)]. ${ }^{1}$ Diabetic patients are reported to have higher Lp(a) levels than non diabetic persons. There are studies which have conclusions that Lp (a) is an independent risk factor for coronary artery disease. ${ }^{2}$ Lipoprotein (a) is also a risk factor for the progression of diabetic nephropathy with overt proteinuria, arterial stiffness in elderly patient and peripheral arterial disease in type 2 DM patients. High serum Lp (a) plays a major role in the occlusion of retinal capillaries leading to proliferative diabetic retinopathy.

\section{Objectives}

- To assess the correlation between diabetic nephropathy with respect to serum levels of Lipoprotein (a) in patients with type 2 diabetes mellitus.

- To assess the association between serum Lipoprotein (a) levels with glycemic status in type 2 diabetes mellitus patients.

\section{Methodology}

The present study was conducted in the Department of Medicine, Navodaya Medical College Hospital and Research Centre, Raichur on patients with type 2 DM during the period of August 2013 to July 2014.

\section{Study design}

One year correlation study.

\section{Study period}

The present study was conducted during August 2013 to July 2014.

\section{Method of collection of data Source of Data}

The present study is done in the department of General Medicine at Navodaya Medical College
Hospital and Research Centre, Raichur over a period of one year. Randomly both inpatients and outpatients diagnosed to have type $2 \mathrm{DM}$ by laboratory reports were taken into the study.

\section{Sample size}

A sample size of 100 cases with type 2 DM were selected for the study.

\section{Inclusion Criteria}

The study includes randomly selected patients with diagnosed Type 2 diabetes mellitus confirmed by previous laboratory reports who are above the age of 30years fulfilling ADA Criteria irrespective of sex. ADA Criteria ${ }^{3}$ for diagnosis of diabetes meliitus: FBS $\geq 126 \mathrm{mg} / \mathrm{dl}$ orHBA1C $\geq 6.5 \%$; or Random plasma glucose $\geq 200 \mathrm{mg} / \mathrm{dL}(11.1 \mathrm{mmol} / \mathrm{L})$ with symptoms of diabetes mellitus.

\section{Exclusion criteria}

1. Patients with Hypothyroidism including subclinical hypothyroidism;

2. Patients with chronic liver disease;

3. Patients with end stage renal disease;

4. Those who are seriously ill and with recent acute illness ( $<3$ months);

5. Those who are chronic alcoholics;

6. Pregnant women;

7. Patients who were already on lipid lowering drugs or glitazones;

8. Females taking Oral contraceptive pills, HRT, Niacin, Corticosteroids etc.

\section{Statistical analysis}

SPSS 19.0 version was used for analysis .Quantitative data analysed in terms mean and SD. Comparison of mean was carried out by using one way ANOVA or students unpaired ' $t$ ' test according to requirement. Association between two variables was found by using chi square test. $\mathrm{P}$ value less than 0.05 was considered to be significant and less than 0.001 was highly significant. 


\section{Results}

The serum Lp (a) levels and the association were studied for a period of one year during August 2013 to July 2014. The findings are tabulated as below

Table 1: Distribution of study population according to Age

\begin{tabular}{|c|c|c|}
\hline Age in yrs & Frequency & Percent \\
\hline$=45$ & 24 & 24.0 \\
\hline $46-55$ & 36 & 36.0 \\
\hline $56-65$ & 37 & 37.0 \\
\hline$=65$ & 3 & 3.0 \\
\hline Total & 100 & 100.0 \\
\hline
\end{tabular}

In this study the age of the patients varied from 40 years to 71 years of age. Majority $(37 \%)$ of the patients belonged to 56 to 65 years age group, followed by $36 \%$ in 46 to 55 years age group, $24 \%$ in less than 45 years age group and $3 \%$ in more than 65 years age group. The findings revealed that as age progressed serum Lp (a) levels progressively increased significantly $(\mathrm{p}=0.028)$.
Table 2: Distribution of study population according to sex

\begin{tabular}{|c|c|c|}
\hline Sex & Frequency & Percent \\
\hline Male & 56 & 56.0 \\
\hline Female & 44 & 44.0 \\
\hline Total & 100 & 100.0 \\
\hline
\end{tabular}

Graph no. 1: Distribution of study population according to sex

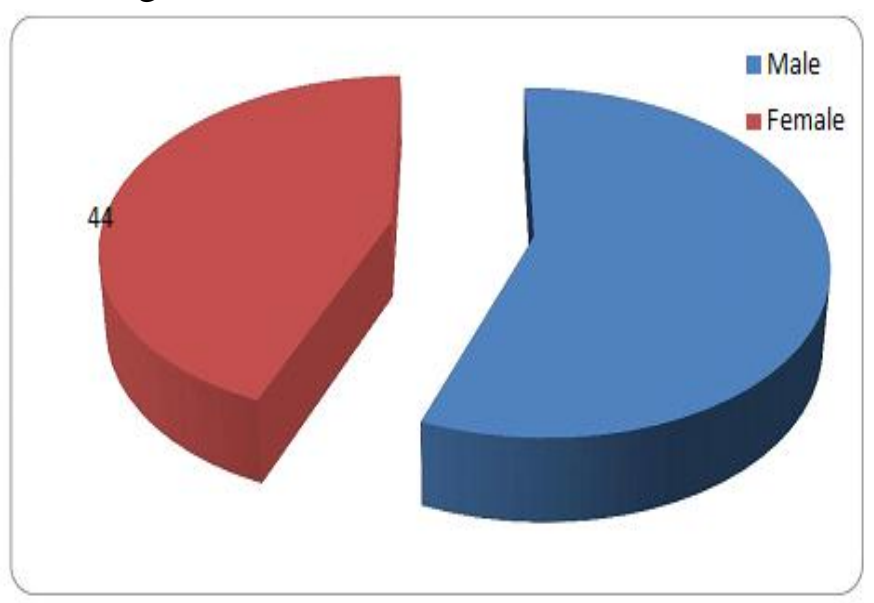

In the present study among 100 patients 56 $(56.0 \%)$ were males and $44(44.0 \%)$ were females with male to female ratio of 1.27: 1 .

Table 3: Distribution of mean Lp(a) according to duration of DM

\begin{tabular}{|c|c|c|c|c|c|c|}
\hline $\begin{array}{l}\text { Duration } \\
\text { of DM }\end{array}$ & $\mathbf{N}$ & $\begin{array}{l}\text { Mean } \\
\text { Lp(a) }\end{array}$ & $\begin{array}{c}\text { Std. } \\
\text { Deviation }\end{array}$ & F & df & $\mathbf{p}$ \\
\hline$<10$ yrs & 19 & 23.83 & 7.22 & \multirow{4}{*}{4.98} & \multirow{4}{*}{3} & \multirow{4}{*}{$\begin{array}{l}0.003 \\
(<0.05)\end{array}$} \\
\hline $10-14$ yrs & 58 & 32.24 & 15.81 & & & \\
\hline $15-19$ yrs & 18 & 37.03 & 15.4 & & & \\
\hline$=20 \mathrm{yrs}$ & 5 & 49.8 & 19.76 & & & \\
\hline
\end{tabular}




\section{JMSCR Vol||06||Issue||09||Page 980-990||September}

Graph no. 2: Distribution of mean Lp(a) according to duration of DM

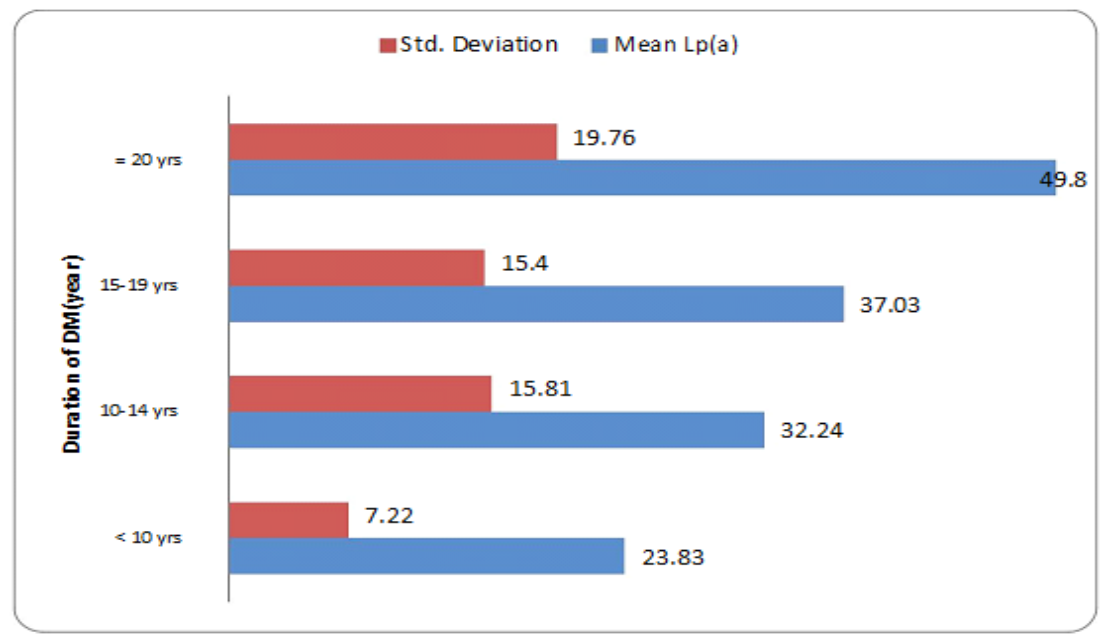

In present study, out of 100 patients, 58 patients had duration of 10 to 14 years with mean $\mathrm{Lp}(\mathrm{a})$ levels of $32.24 \mathrm{mg} / \mathrm{dL}$. As duration of diabetes increased so did the mean $\mathrm{Lp}(\mathrm{a})$ levels, which was statistically significant $(\mathrm{p}=0.003)$

Table 4: Distribution of mean LP(a) according to urine ACR

\begin{tabular}{|c|r|r|c|c|c|c|}
\hline Urine & N & Mean & Std. & t & df & p \\
mcg/mg & & Lp(a) & Deviation & & & \\
\hline$<30$ & 40 & 24.72 & 10.92 & & 98 & .0001 \\
& & & & & & \\
$(<0.001)$
\end{tabular}

In the present study results suggested that as the urinary ACR levels increased, the mean Lp(a) levels also increased. 60 patients out of 100 diabetic patients had urinary ACR levels more than $30 \mathrm{mcg} / \mathrm{mg}$ with mean $\mathrm{Lp}$ (a) levels of
$37.04 \mathrm{mg} / \mathrm{dl}$ as compared to mean $\mathrm{Lp}$ (a) level of $24.72 \mathrm{mg} / \mathrm{dl}$ in patients with urinary ACR less than $30 \mathrm{mcg} / \mathrm{mg}$. These findings were statistically significant $(\mathrm{p}=0.0001)$

Graph no. 3: Distribution of mean LP a according to urine ACR

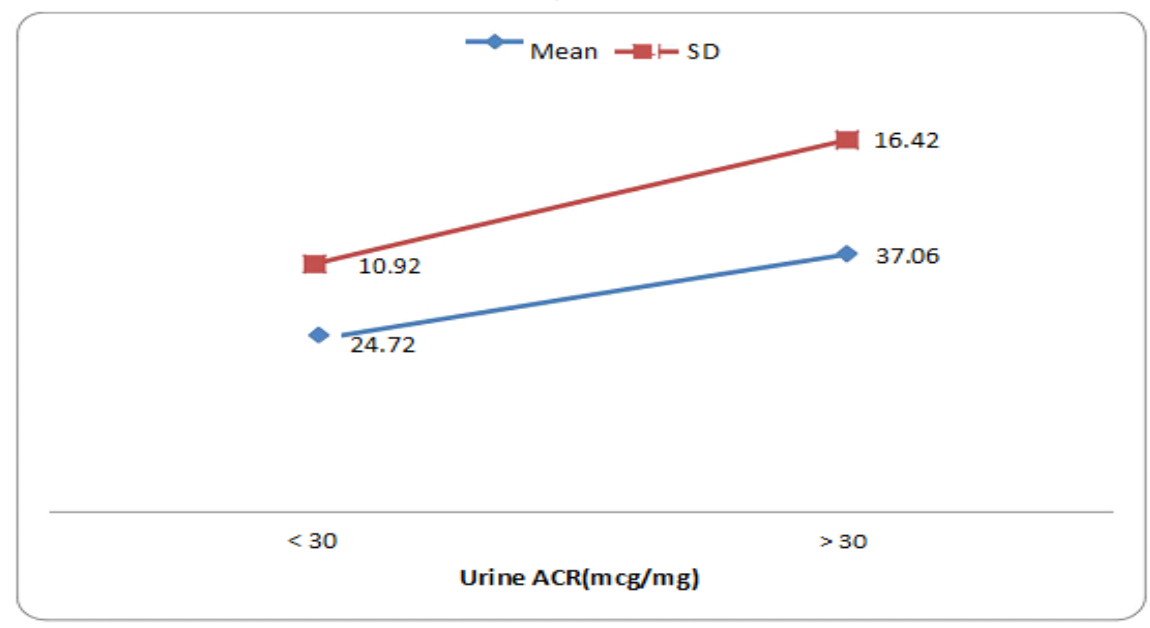


Table 5: Distribution of Mean Lp(a) levels according to Effective creatinine clearance

\begin{tabular}{|c|c|c|c|c|c|c|}
\hline $\begin{array}{c}\text { Effective } \\
\text { creatinine } \\
\begin{array}{c}\text { clearance } \\
\text { (ml/min.) }\end{array}\end{array}$ & N & M ean & Std. & F & df & p \\
\hline $21-40$ & 24 & 37.97 & 15.96 & & & \\
\hline $41-60$ & 41 & 33.09 & 16.19 & \multirow{2}{*}{4.85} & 3 & \multirow{2}{*}{$(<0.05)$} \\
\hline $61-80$ & 15 & 32.88 & 16.57 & & & \\
\hline$>80$ & 20 & 21.33 & 6.81 & & & \\
\hline
\end{tabular}

In the present study, comparison between creatinine clearance and mean $\operatorname{Lp}(\mathrm{a})$ levels showed an inverse relationship that, as creatinine clearance decreased mean $\mathrm{Lp}(\mathrm{a})$ levels increased which is of statistical significance $(\mathrm{p}=0.003)$.

Graph no. 4: Distribution of Mean Lp(a) levels according to Effective creatinine clearance

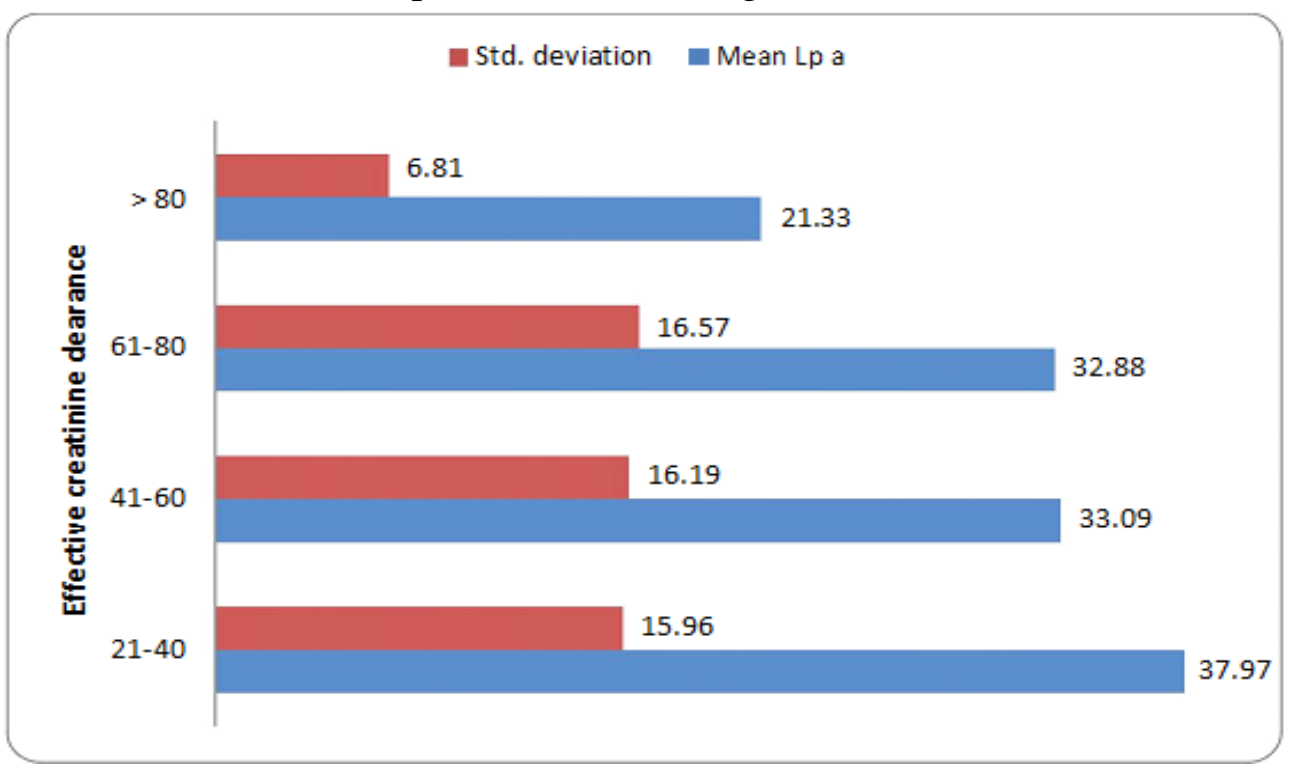

Table 6: Comparison between Serum creatinine levels and mean Lp(a) level

\begin{tabular}{|c|c|c|c|c|c|c|}
\hline $\begin{array}{c}\text { Serum } \\
\text { creatinine(mg/dl) }\end{array}$ & $\mathbf{N}$ & $\begin{array}{l}\text { Mean } \\
\text { Lp(a) } \\
\text { level }\end{array}$ & $\begin{array}{c}\text { Std. } \\
\text { Deviation }\end{array}$ & $\mathrm{F}$ & df & $\mathbf{p}$ \\
\hline$<1$ & 16 & 21.5 & 7.67 & \multirow{3}{*}{12.878} & \multirow{3}{*}{2} & \multirow{3}{*}{$\begin{array}{l}0.0001 \\
(<0.001)\end{array}$} \\
\hline $1.0-1.5$ & 46 & 28.39 & 10.82 & & & \\
\hline$>1.5$ & 38 & 40.47 & 18.76 & & & \\
\hline
\end{tabular}


In the present study of 100 diabetic patients, 16 patients had serum creatinine less than $1 \mathrm{mg} / \mathrm{dl}$. 46 patients had serum creatinine level in between 1 to $1.5 \mathrm{mg} / \mathrm{dl}$ and 38 patients had serum creatinine than of $1.5 \mathrm{mg} / \mathrm{dl}$, these patients had progressively increasing values of mean Lp(a) levels. Patients with serum creatinine levels more than $1.5 \mathrm{mg} / \mathrm{dl}$ had maximum mean $\mathrm{Lp}$ (a) level of $40.48 \mathrm{mg} / \mathrm{dl}$ when compared to mean $\mathrm{Lp}$ (a) level of 21.5 $\mathrm{mg} / \mathrm{dl}$ among patients with serum creatinine of less than $1 \mathrm{mg} / \mathrm{dl}$. These findings are of statistical significance $(\mathrm{p}=0.0001)$.

Graph no.5: Comparison between Serum creatinine levels and mean Lp(a) level

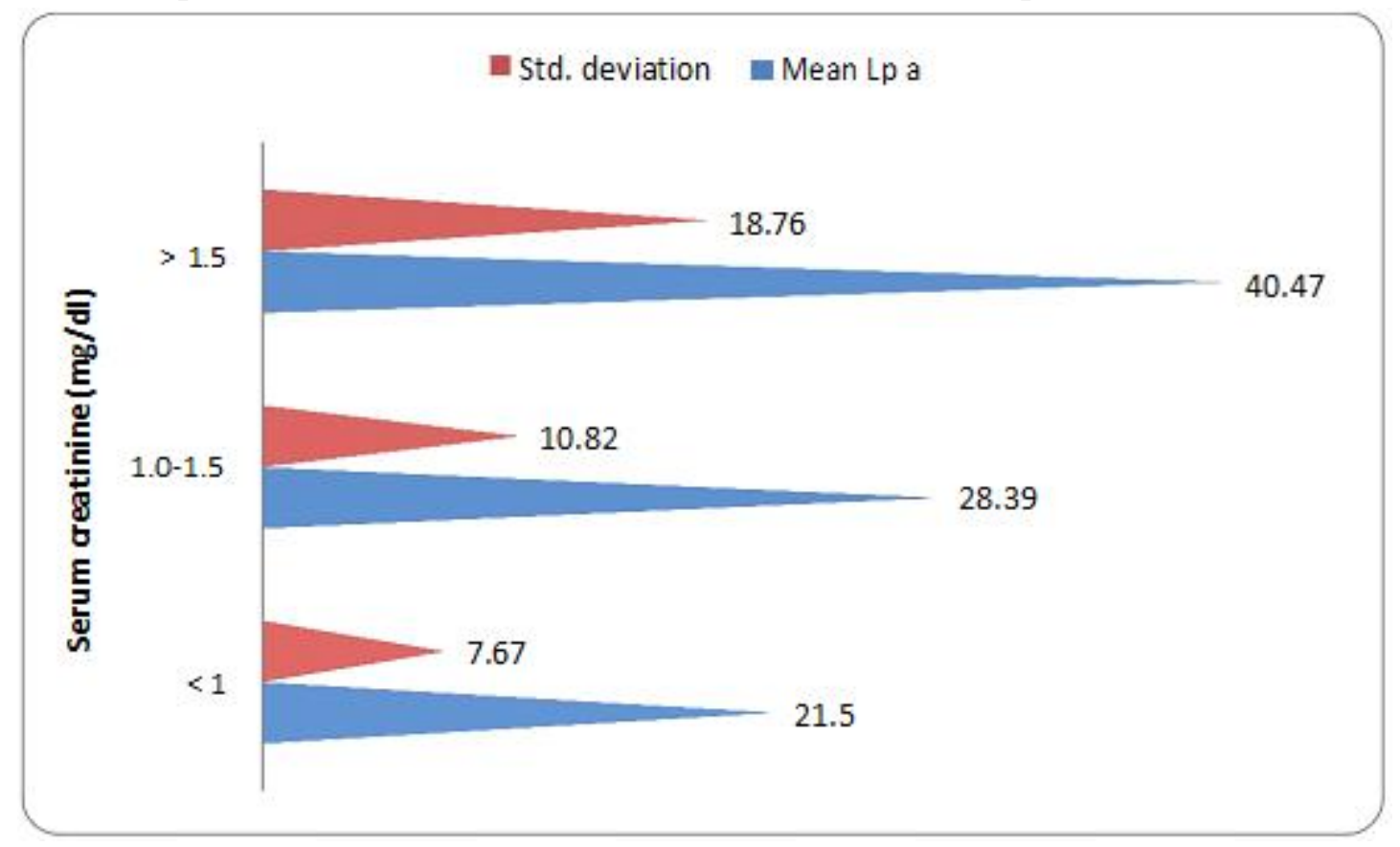

Table 7: Comparison of HbA1C with mean Lp (a) level

\begin{tabular}{|c|c|c|c|c|c|c|}
\hline $\begin{array}{c}\text { HbAlC } \\
\text { level (\%) }\end{array}$ & $\mathbf{N}$ & $\begin{array}{c}\text { Mean Lp } \\
\text { (a) }\end{array}$ & $\begin{array}{c}\text { Std. } \\
\text { Deviation }\end{array}$ & $\mathbf{F}$ & df & p \\
\hline$<6$ & 3 & 27.33 & 11.23 & \multirow{5}{*}{4.353} & \multirow{5}{*}{4} & \multirow{5}{*}{$\begin{array}{l}0.003 \\
(<0.05)\end{array}$} \\
\hline $6-7$ & 22 & 24.23 & 14.46 & & & \\
\hline $7-8$ & 19 & 25.53 & 12.14 & & & \\
\hline $8-9$ & 25 & 37.74 & 14.63 & & & \\
\hline$>9$ & 31 & 36.91 & 16.39 & & & \\
\hline
\end{tabular}




\section{JMSCR Vol||06||Issue||09||Page 980-990||September}

Graph no. 6 : Comparison of HbA1C with mean Lp (a) level

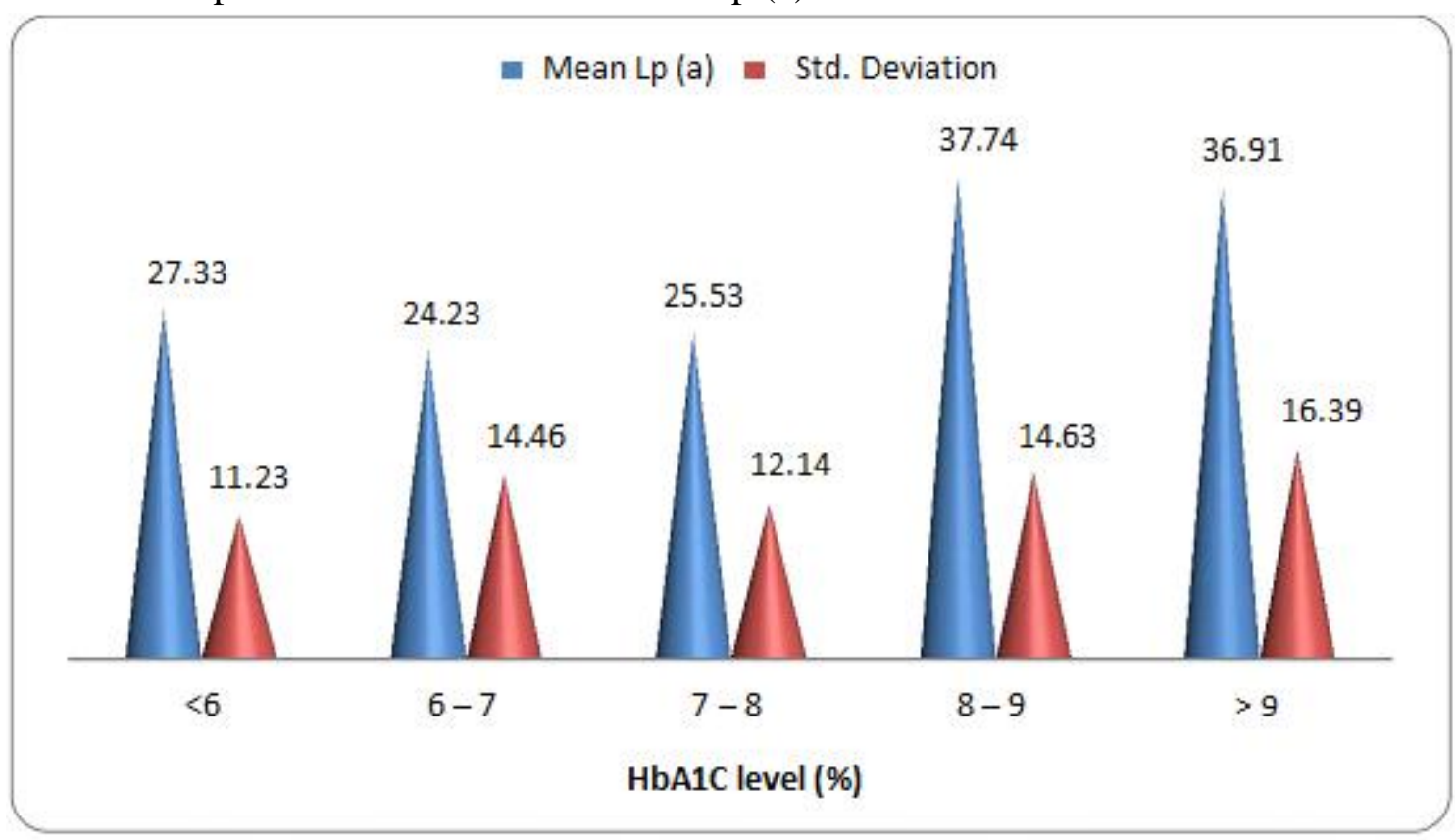

In the present study, 31 patients (31\%) had HbA1c levels more than $9.0 \%$ with mean $\mathrm{Lp}(\mathrm{a})$ of $36.91 \mathrm{mg} / \mathrm{dl}$. In 25 patients $(25 \%)$ had $\mathrm{HbA1c}$ levels between 8 to $9 \%$ with mean $\mathrm{Lp}(\mathrm{a})$ levels of $37.74 \mathrm{mg} / \mathrm{dl}, 22$ patients $(22 \%)$ had HbA1c levels between 6 to $7 \%$ with mean $\mathrm{Lp}$ (a) levels of $24.23 \mathrm{mg} / \mathrm{dl}, 19$ patients (19\%) had HbA1c levels in between 7 to $8 \%$ with mean $\mathrm{Lp}$ (a) levels of $25.53 \mathrm{mg} / \mathrm{dl}$, and three patients had HbA1c levels less than $6 \%$ with mean Lp(a) levels of $27.33 \mathrm{mg} / \mathrm{dl}$. Statistically significant trend was observed, where the HbA1c levels increased, mean Lp(a) levels also increased linearly except for two HbAlc levels.

Table 8: Comparison of fasting blood sugar level and mean Lp (a) level

\begin{tabular}{|c|c|c|c|c|c|c|}
\hline $\begin{array}{c}\text { Fasting } \\
\text { blood } \\
\text { sugar(mg/dl) }\end{array}$ & $\mathbf{N}$ & $\begin{array}{l}\text { Mean } \\
\text { Lp (a) }\end{array}$ & $\begin{array}{c}\text { Std. } \\
\text { Deviation }\end{array}$ & $\mathrm{F}$ & df & p \\
\hline$<120$ & 22 & 24.25 & 8.4 & \multirow{5}{*}{5.61} & \multirow{5}{*}{4} & \multirow{5}{*}{$\begin{array}{l}0.0001 \\
(<0.001)\end{array}$} \\
\hline $121-150$ & 16 & 21.91 & 10.73 & & & \\
\hline $151-250$ & 53 & 37.19 & 16.92 & & & \\
\hline $251-350$ & 8 & 36.2 & 14.81 & & & \\
\hline$>350$ & 1 & 43 & 0 & & & \\
\hline
\end{tabular}

The present study results suggested that as the FBS values increased, the mean Lp(a) levels also increased. Maximum mean Lp(a) levels were found in the group of FBS more than 350 $\mathrm{mg} / \mathrm{dl}$. Majority of patients $(53 \%)$ belonged to group with FBS levels between 151 to 250 $\mathrm{mg} / \mathrm{dl}$ with mean Lp(a) levels of $37.19 \mathrm{mg} / \mathrm{dl}$. Statistical test revealed highly significant differences between mean $\operatorname{Lp}(\mathrm{a})$ levels at different FBS levels. 


\section{JMSCR Vol||06||Issue||09||Page 980-990||September}

Graph no. 7: Comparison of fasting blood sugar level and mean Lp (a) level

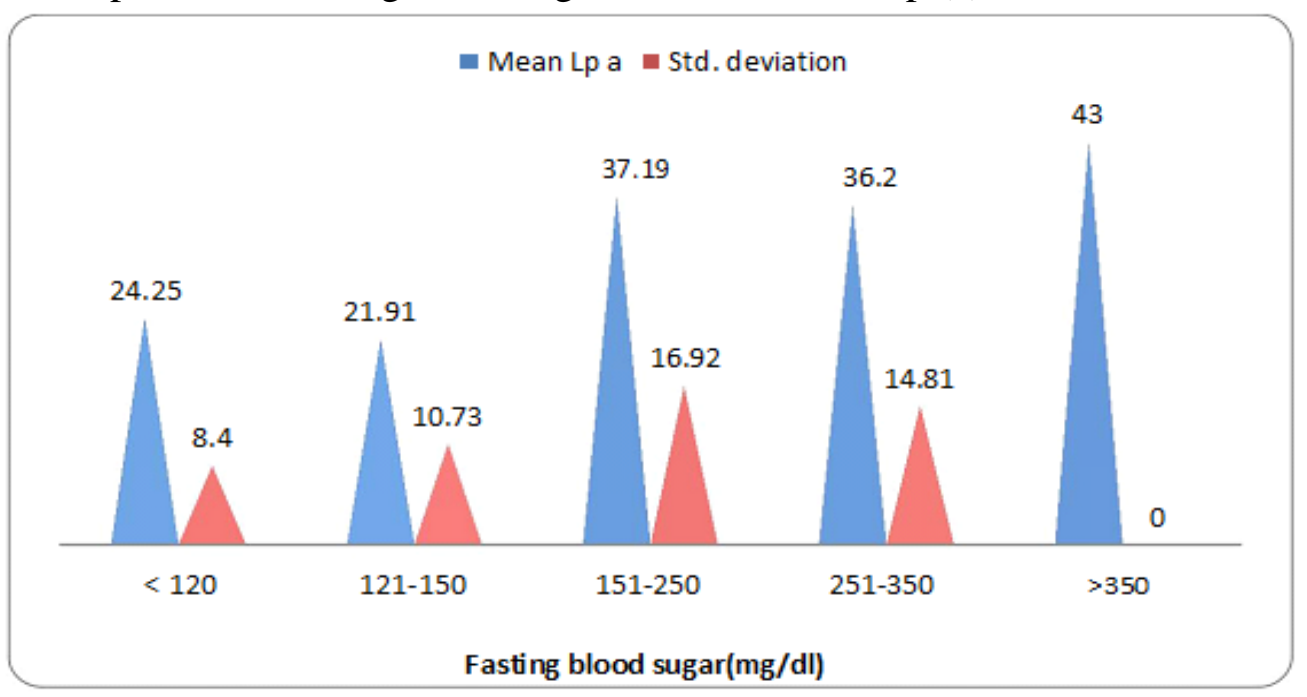

Table 9: Comparison of postprandial blood sugar level and mean Lp (a) level

\begin{tabular}{|c|c|c|c|c|c|c|}
\hline PPBS (mg/d) & $\mathbf{N}$ & Mean & Std. & F & df & p \\
\hline$<200$ & 36 & 24.88 & 9.83 & & & \\
\hline $201-300$ & 50 & 34.34 & 16.66 & \multirow{2}{*}{4.985} & 3 & \multirow{2}{*}{0.003} \\
\hline $301-400$ & 11 & 41.73 & 19.03 & & & \\
\hline$>400$ & 3 & 38.66 & 14.01 & & & \\
\hline
\end{tabular}

While comparing PPBS levels with Lp(a) levels, the results suggested that as PPBS values increased, the mean $\mathrm{Lp}$ (a) levels also increased except at PPBS levels above 400mg/dl. This could be due to diabetic status in patients with insulin therapy. Maximum Lp(a) levels were found in PPBS level of 301- $400 \mathrm{mg} / \mathrm{dl}$. The one way ANOVA test revealed a significant differences between mean $\mathrm{Lp}(\mathrm{a})$ values of patients with different PPBS levels. On the whole, the above results indicate that better the glycemic control, lesser the mean Lp(a) values.

Graph no. 8: Comparison of postprandial blood sugar level and mean Lp (a) level

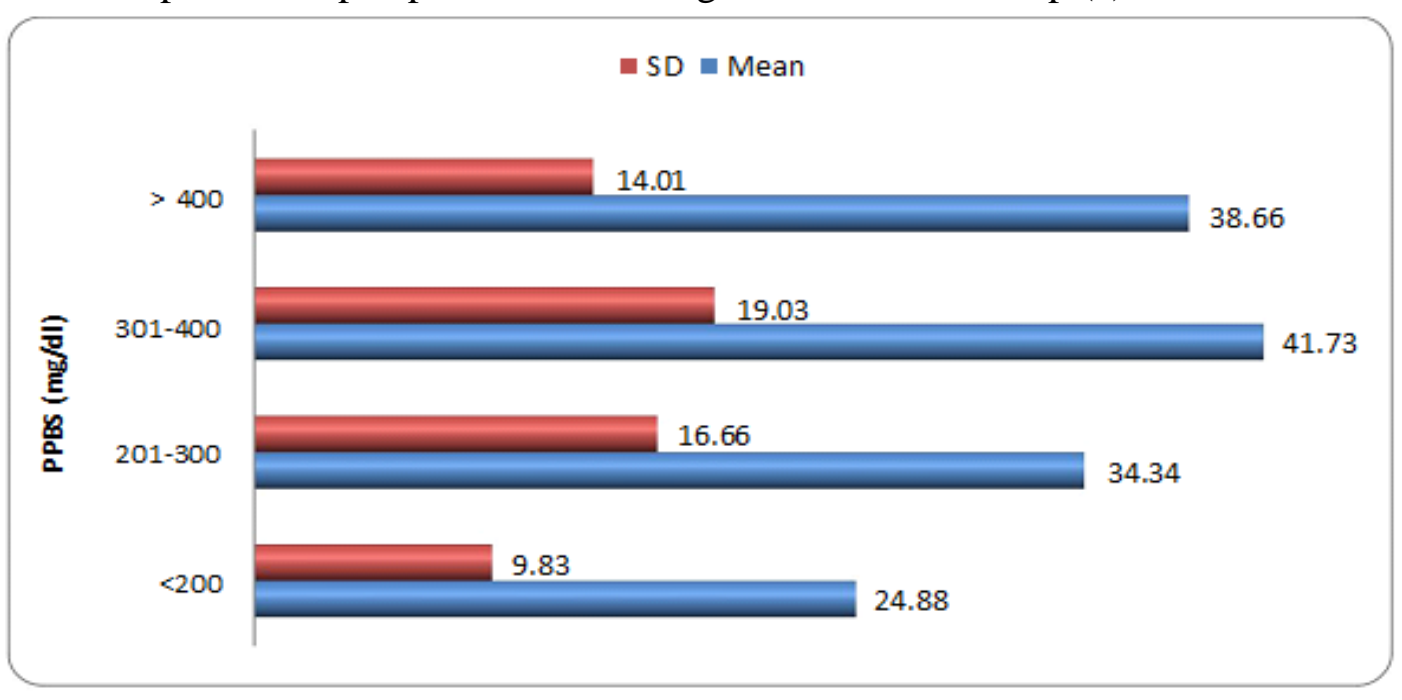




\section{Discussion}

Diabetes Mellitus is a chronic disease that requires long term medical attention both to limit the development of its devastating complications and to manage them when they do occur. Therefore the present study has been undertaken to assess the serum concentration of Lp (a) levels and diabetic nephropathy which develop in type $2 \mathrm{DM}$ patients. In the present study, 100 patients were included who were detected to have laboratory proven type $2 \mathrm{DM}$ fulfilling ADA criteria. ${ }^{3}$ These diabetic patients were either on diet with oral hypoglycaemic agents (OHA) and or on insulin therapy. The metabolic status, prevalence of diabetes and various diabetic complications were assessed by detailed history, physical examination and neurological examination and laboratory analysis.

\section{Mean Lipoprotein (a) and age and sex}

In the present correlation study of 100 diabetic patients, the serum levels of $\operatorname{Lp}(\mathrm{a})$ was studied in patients, aged between 40 to 71 years with male : female ratio of 1.27:1 with duration of diabetes varying from 6 years to 21 years. The maximum number of patients belonged in the 56 to 65 years of age group. A highly significant relationship was found between $\mathrm{Lp}$ (a) and increasing age in these patients.

In this study, we found that there was no much difference in serum $\mathrm{Lp}$ (a) levels between males and females who had mean Lp(a) levels of $31.85 \mathrm{mg} / \mathrm{dl}$ and $31.92 \mathrm{mg} / \mathrm{dl}$ respectively.

\section{Mean Lipoprotein (a) and duration of diabetes}

In the present study, the serum levels of Lp (a) was studied in patients with duration of diabetes varying from 6 years to 21 years. The maximum number of patients had duration of diabetes ranging between 10 to 14 years. A statistically significant relationship was found between $\mathrm{Lp}$ (a) and duration of diabetes. Higher Lp(a) levels among patients with a longer duration of diabetes may be related to lower plasma insulin levels in such individuals. In a study on 144 subjects, higher $L p(a)$ levels were observed among those with a longer duration of diabetes ${ }^{4}$. Similar observations were made in another study done to determine association of Lp (a) with basal insulin levels in type 2 diabetes mellitus patients ${ }^{5}$.

\section{Lipoprotein (a) and diabetic nephropathy}

In the present study, 16 patients had serum creatinine less than one $\mathrm{mg} / \mathrm{dl}$ with mean Lp (a) of $21.5 \mathrm{mg} / \mathrm{dL}$ and 46 patients had creatinine levels between 1 to $1.5 \mathrm{mg} / \mathrm{dL}$ with mean Lp (a) levels of $28.39 \mathrm{mg} / \mathrm{dL}$ and 38 patients had creatinine levels of more than $1.5 \mathrm{mg} / \mathrm{dL}$ with mean Lp (a) level of $40.47 \mathrm{mg} / \mathrm{dL}$.

When serum Lp (a) levels were compared with serum creatinine levels, the mean Lp (a) levels were found to be progressively increasing , which was statistically significant $(\mathrm{p}=0.0001)$. Previous studies also revealed that patients with nephropathy had significantly higher Lp (a) levels than patients without nephropathy. Further provoke into the issue and we calculated creatinine clearance in these study population and it showed that as creatinine clearance decreased (ECCR of 21 to $40 \mathrm{had}$ mean Lp (a) of $37.97 \mathrm{mg} / \mathrm{dl}$ and ECCR of more than 80 had mean Lp (a) of $21.33 \mathrm{mg} / \mathrm{dL}$ (p 0.003). A significant inverse correlation of serum Lp (a) with effective creatinine clearance and a statistically significant correlation between the effective creatinine clearance and mean Lp (a) levels were observed. Also very high levels $\mathrm{Lp}$ (a) levels have been documented in patients with non diabetic chronic renal failure ${ }^{6}$.

In present study, When Urinary ACR values were compared with mean $\mathrm{Lp}(\mathrm{a})$ levels, the findings showed $L p(a)$ levels were increased in patients with microalbuminuria and overt proteinuria than in patients with normoalbuminuria which was statistically significant $(p=0.0001)$. In a study, increased 
Lp(a) levels were found in patients with type 2 DM with overt proteinuria ${ }^{7}$.

This suggests that renal dysfunction is associated with raised serum Lp (a) levels. Patients with nephropathy, proteinuria (microalbuminuria), with high levels of Lp (a) are probably because of decreased renal excretion, rather than raised Lp (a) causing nephropathy. It can be thus concluded that serum Lp (a) levels are raised in diabetic nephropathy and probably it is due to renal dysfunction.

\section{Lp (a) and blood sugar levels}

In the present study, we found that as FBS values increased, the mean Lp (a) levels also increased. Maximum Lp (a) levels of 43.0 $\mathrm{mg} / \mathrm{dL}$ were found in the FBS more than 350 $\mathrm{mg} / \mathrm{dL}$ group and it was statistically significant $(p=0.0001)$. Also we found that as PPBS values increased, the mean Lp (a) levels also increased except at PPBS level more than $400 \mathrm{mg} / \mathrm{dl}$.

The correlation between mean Lp (a) and PPBS were also statistically significant $(\mathrm{p}=0.003)$. Similar findings were observed when mean Lp (a) levels were compared with HbA1c, statistically significant trend was observed, where the HbA1c levels increased, mean Lp(a) levels also increased linearly. In another study, on association of $\mathrm{HbA} 1 \mathrm{c}$ with lipoprotein (a) in type 2 diabetes mellitus also showed significantly association of higher Lp(a) levels with higher HbA1c levels $(\mathrm{p}<0.001)^{8}$. On the whole the results of this study indicate that better the glycemic control, lesser the mean Lp (a) levels.

In a study on Lipoprotein(a) concentration in non-insulin-dependent diabetes mellitus and borderline hyperglycemia there was no correlation between Lp (a) levels and FPG ( $p=.030$ )and they concluded that Lp (a) levels are similarin individuals with NIDDM, borderline hyperglycemia, and normoglycemia? Another study on Lp (a) revealed that mean Lp (a) levels were not influenced by type of hypoglycemic treatment or blood glucose level, and Lp (a) concentrations are not related to glycemia ${ }^{10}$. In another study on Insulin and 2Hour Glucose Levels Are Inversely Related to Lp (a) Concentrations Controlled for LPA Genotype. There were significant correlations of $\mathrm{Lp}$ (a) with insulin and glucose concentrations, especially for insulin ${ }^{11}$. Hence it may be concluded that Lp (a) is another, among many lipoproteins, that is associated with the metabolic syndrome characterized by insulin resistance.

\section{Conclusion}

The present correlation study was conducted in the Department of General Medicine, Navodaya Medical College Hospital and Research Centre, Raichur on 100 patients, detected to have laboratory proven type $2 \mathrm{DM}$, confirmed by ADA criteria ${ }^{12}$. The serum Lp (a) levels and the association with diabetic nephropathy were studied for a period of one year during August 2013 to July 2014. After analyzing the results the following conclusions were drawn.

1. The $\mathrm{Lp}$ (a) values progressively increased as age increased.

2. The Lp (a) levels were maximum above 65 years

3. The Lp (a) levels increased as duration of diabetes increased.

4. Patients with diabetic nephropathy had statistically significant increased levels of Lp (a). But the effective creatinine clearance ratio in these diabetics had an inverse relation to mean $\mathrm{Lp}$ (a) levels.

5. Present study indicated that better the glycemic control, lesser the mean Lp (a) levels.

Hence Lp (a) may be an independent risk factor for the development of diabetic nephropathy in type 2 DM. However further studies on larger sample size may be helpful to confirm the above findings. 


\section{Summary}

Diabetes is the most common endocrine disorder and a burdensome chronic disease in the world today.

The objective of the present study was to assess the microvascular complication- diabetic nephropathy in patients with type $2 \mathrm{DM}$ with respect to their serum levels of $L p(a)$.

The present correlation study was conducted in the Department of General Medicine, Navodaya medical college Hospital and Research Centre, Raichur on 100 patients, detected to have laboratory proven type $2 \mathrm{DM}$. The serum Lp (a) levels and the association with diabetic nephropathy were studied for a period of one year during August 2013 to July 2014.

The results of the study showed that, Lp (a) values progressively increased as age increased. DM patients with diabetic nephropathy had increased levels of mean Lp (a) levels. Present study indicated that better the glycemic control, lesser the mean Lp (a) levels. As the sugar increased, Lp (a) levels also increased. Hence Lp(a) may be an independent risk factor for the development of diabetic nephropathy in type 2 DM patients.

\section{Bibliography}

1. Mann JI, Lewis B, Shepherd J, Winder AF, Fenster S, Rose L et al. Blood lipid concentrations and other cardiovascular risk factors. Br Med J 1988; 296: 1702-6.

2. Marcovina SM, Koschinsky ML. Lipoprotein (a) as risk factor for coronary artery disease. Am J Cardiol 1998; 82; 57U-66U.

3. Diagnosis and classification of diabetes mellitus. Diabetes Care. Jan 2010; 33 Suppl 1:S62-9.

4. Radhakrishnan Chandni and Kollengode Parameswaran Ramamoorthy, Lipoprotein (a) in type 2 diabetic subjects and its relationship to diabetic microvascular complications. World J Diabetes. 2012 May 15; 3(5): 105-109.
5. Habib SS, Aslam M et al. Lipoprotein (a) is associated with basal insulin levels in patients with type 2 Diabetes Mellitus. Arq Bras Cardiol 2009 Jul; 93(1):28-33.

6. Emin K, Faruk O, Zeki A, Ramazan YM, Ali SR, Sami IS. Relationship Between Serum Lipoprotein (a) Levels and Retinopathy in Patients With Type 2 Diabetes. Annal Ophthalmol 2002; 34 (4): 198-203.

7. Song KH, Ko SH, Kim HW, Ahn YB, Lee JM, et al. Prospective study of lipoprotein (a) as a risk factor for deteriorating renal function in type 2 diabetic patients with overt proteinuria. Diabetes care.2005 Jul;28(7):1718-23.

8. Lakhotia M, Gehlot RS, Jain P, Sharma S, Singh M. Lipoprotein (a) in Type 2 Diabetic Subjects in relation to Diabetic Microvascular Complications. JIACM 2003; 4(4): 304-7.

9. Khare KC, Raman PG, Bhatnagar AD, Bhavsar R. Serum Lp(a) levels in patients of diabetes mellitus Int $\mathrm{J}$ Diab Dev countries 2000; 20: 79-83.

10. Habib SS, Aslam M, Naveed AK, Razi MS. Comparison of lipid profiles and lipoprotein (a) levels in patients with type 2 diabetes mellitus during oral hypoglycemic or insulin therapy. Saudi Med J 2006; 27 : 174-80.

11. Rainwater DL, Haffner SM. Insulin and 2hour glucose levels are inversely related to Lp (a) concentrations controlled for LPA genotype. Arterioscler Thromb Vasc Biol 1998; 18(8): 1335-41.

12. Diagnosis and classification of diabetes mellitus. Diabetes Care. Jan 2010; 33 Suppl 1:S62-9. 